\title{
Investment appraisal of automatic milking and conventional milking technologies in a pasture-based dairy system
}

\author{
J. Shortall, ${ }^{*}{ }^{1}$ L. Shalloo, ${ }^{*}$ C. Foley, ${ }^{*}$ R. D. Sleator, $\dagger$ and B. O’Brien* \\ *Teagasc, Animal \& Grassland Research and Innovation Centre, Moorepark, Fermoy, Co. Cork, Ireland \\ †Department of Biological Sciences, Cork Institute of Technology, Bishopstown, Co. Cork, Ireland
}

\begin{abstract}
The successful integration of automatic milking (AM) systems and grazing has resulted in AM becoming a feasible alternative to conventional milking $(\mathrm{CM})$ in pasture-based systems. The objective of this study was to identify the profitability of AM in a pasturebased system, relative to $\mathrm{CM}$ herringbone parlors with 2 different levels of automation, across 2 farm sizes, over a 10-yr period following initial investment. The scenarios which were evaluated were (1) a medium farm milking 70 cows twice daily, with 1 AM unit, a 12-unit CM medium-specification (MS) parlor and a 12-unit CM high-specification (HS) parlor, and (2) a large farm milking 140 cows twice daily with 2 AM units, a 20-unit CM MS parlor and a 20 -unit CM HS parlor. A stochastic whole-farm budgetary simulation model combined capital investment costs and annual labor and maintenance costs for each investment scenario, with each scenario evaluated using multiple financial metrics, such as annual net profit, annual net cash flow, total discounted net profitability, total discounted net cash flow, and return on investment. The capital required for each investment was financed from borrowings at an interest rate of $5 \%$ and repaid over 10-yr, whereas milking equipment and building infrastructure were depreciated over 10 and $20 \mathrm{yr}$, respectively. A supporting labor audit (conducted on both $\mathrm{AM}$ and $\mathrm{CM}$ farms) showed a 36\% reduction in labor demand associated with AM. However, despite this reduction in labor, MS CM technologies consistently achieved greater profitability, irrespective of farm size. The AM system achieved intermediate profitability at medium farm size; it was $0.5 \%$ less profitable than HS technology at the large farm size. The difference in profitability was greatest in the years after the initial investment. This study indicated that although milking with AM was
\end{abstract}

Received April 1, 2016.

Accepted May 29, 2016

${ }^{1}$ Corresponding author: john.shortall@teagasc.ie less profitable than MS technologies, it was competitive when compared with a CM parlor of similar technology. Key words: automatic milking system, conventional milking system, milking technology, labor demand, profitability

\section{INTRODUCTION}

The first automatic milking (AM) system was commercialized in the Netherlands in 1992 and the concept has since become common around the world, with more than 10,000 farms using the technology (de Koning, 2011). It is envisaged that up to $50 \%$ of new milking parlor installations in many European Union (EU) countries will be AM (O'Brien et al., 2015b). However, the vast majority of these are integrated with indoor cow-management systems. The combination of AM and grazing was first reported in the early 2000s in Australia and New Zealand by Greenall et al. (2004) and Jago et al. (2004). The successful integration of AM and grazing has resulted in AM systems becoming a feasible alternative to conventional milking (CM) in pasturebased systems worldwide. Given the comparative advantage that grass-based systems have in reducing total costs of production (Dillon et al., 2005), as well as the increased sustainability associated with grass-based systems (O'Brien et al., 2012b), it is essential that the adoption of AM does not lead to a reduction of the proportion of grazed grass in the cow diet, as shown by van Dooren et al. (2004). This is also important from an international perspective, as van den Pol van Dasselaar et al. (2010) demonstrated that in the Netherlands the greater the proportion of grazed grass consumed by the cow, the larger the income profit compared with nongrazing farms; Hanson et al. (1998) and Hofstetter et al. (2014) showed that grazing systems had a higher return than confinement systems in the United States and Switzerland, respectively. Milk produced from grass can now command a premium price with the largest milk processor in the Netherlands, FrieslandCampina, offering milk producers a price incentive to increase the time cows spend at grass (Reijs et al., 2013). This can 
create potential opportunities for new markets for dairy produce, as the green image associated with cows grazing pasture continues to appeal to consumers due to the improved milk quality (Lock and Garnsworthy, 2003) and animal health (Thomsen et al., 2007). Innovative methods of pasture management have increased the compatibility of AM with grazing (Lyons et al., 2013), whereas Nieman et al. (2015) investigated the optimal animal genotype and supplementation type for a pasture-based AM system in the United States. Although these studies have shown that AM can be integrated into grazing systems, an economic evaluation specific to pasture-based systems is required to allow farmers to objectively assess if an investment in AM would be prudent given the specific costs and economic returns of producing milk from grazed grass. Irrespective of region or production system, economics are a vital pillar of sustainability and should be focused on regardless of intensity of AM systems within a country. This is particularly relevant in an Irish context at the present time, given the rapid increase in popularity of the AM system and the abolition of the EU milk quota regimen, many farmers are faced with a decision regarding investment in milking technology.

The 2 main reasons cited for investing in AM are social and economic (Bijl et al., 2007). The most prevalent social reason is undoubtedly the association of AM with the reduced labor demand on farms and, in particular, greater time flexibility (Hogeveen et al., 2004) due to reduced unsocial labor requirements. The milking task in a conventional parlor is a laborintensive process which takes place once to thrice, but mostly twice daily for up to $300 \mathrm{~d}$ of the year (Jago and Woolford, 2002). This accounts for up to $33 \%$ of total dairy labor input on pasture-based dairy farms (O'Donovan et al., 2008). Additionally, it is a task that rarely occurs during normal business hours, which can make it a challenging task to attract and retain skilled labor (Tarrant and Armstrong, 2012). Whereas studies may disagree with regard to the magnitude of the reduction in labor associated with AM (Sonck, 1995; Mathijs, 2004; Bijl et al., 2007), all of the studies are in agreement that AM reduces labor demand as it eliminates physical tasks associated with milking, such as milking cluster attachment and detachment, and some herding of cows for milking. The labor associated with AM systems includes visual monitoring of milking and cow data, cleaning, and checking of attention lists on AM systems (Steeneveld et al., 2012). Consequently, farmers with AM systems report improved physical and mental health and improved lifestyles (Mathijs, 2004) associated with the investment in AM. Furthermore, $\mathrm{AM}$ allows operators some time flexibility, as their pres- ence is no longer required at specific milking times; this can create potential for alternative engagement, which might include off-farm employment. This reduction in physical labor demand and the increase in time flexibility represent an improved social aspect to dairy farming, and these also were the main reasons cited by Dutch dairy farmers for the adoption of AM (Hogeveen et al., 2004).

However, AM is regarded as a system that requires 2 to 3 times more capital, initially, than the CM herringbone parlor (Rotz et al., 2003). Higher capital costs, combined with higher running costs, has prompted the majority of studies examining the economics of AM to suggest, that AM was not cost effective when examined solely on a financial return basis (Dijkhuizen et al., 1997; Rotz et al., 2003; Jago et al., 2006). Moyes et al. (2014) established that concerns for farmers in the United States included cash flow and profitability when transitioning to AM systems. However, many such studies examined the economics of AM relative to conventional parlors that had little automation. It is crucially important to establish the economic parameters of AM relative to $\mathrm{CM}$ herringbone parlors with different levels of automation and technology.

To obtain finance for modernization and mechanization in the future, dairy farmers will be required to develop robust financial plans to allow investment to provide optimal labor efficiency and financial return. Many complex factors must be considered and simulation models have been developed to identify optimum investment strategies. These are necessary to understand the relationship between capital costs, financing structures, labor productivity, inflation, farm inputs and outputs, and price volatility (Rotz et al., 2003; Shalloo et al., 2004; Jago et al., 2006). Such models have the ability to assess the financial return to the farm over an extended period, based on the rate of capital investment and allocation of resources. The objective of the current study was to identify the profitability of AM relative to $\mathrm{CM}$ herringbone parlors with 2 different levels of technology, over a 10-yr period across 2 farm sizes, in a pasture-based system using several different financial metrics.

\section{MATERIALS AND METHODS}

To examine the economic parameters associated with investing in AM technology compared with $2 \mathrm{CM}$ parlors with different technology levels (medium and high), and suitable for 2 different herd sizes (70 and 140 cows), several different components of the systems were measured and defined. These included initial machine and infrastructural investment costs; annual machine 
maintenance; energy use; and machine running costs and on-farm dairy labor input, all of which were incorporated into the Moorepark Dairy Systems Model [MDSM; Shalloo et al. (2004); see model description below]. Three different parlor types were assessed: (1) an AM system, (2) CM system of medium specification (MS), and (3) CM system of high specification (HS; see scenario description below). These systems were evaluated as relevant to 2 different farm sizes: a medium-sized farm (MF) milking 70 cows and largesized farm (LF) milking 140 cows.

\section{Scenario Description}

All 6 milking technology investment scenarios were simulated based on the assumption that the respective farm operated a spring-calving, pasture-based dairy system and where existing milking facilities on the farm were outdated - thus requiring a completely new milking infrastructure on a green-field site. The 6 investment scenarios may be described as follows.

- Automatic milking system (AMS) single unit (AMS-SU): 1 AMS unit milking 70 cows twice daily.

- Twelve-unit MS CM parlor (12MS): 12-unit herringbone milking parlor, milking 70 cows twice daily with MS technology (batch feeders in the milking parlor and swing-over arms).

- Twelve-unit HS CM Parlor (12HS): 12-unit herringbone milking parlor milking 70 cows twice daily with HS technologies (individual electronic cow feeders, swing-over arms, automatic cluster removers, electronic milk meters, automatic identification, automatic drafting, automatic washer, automatic cluster cleaning between individual cow milkings, and an electronic milk diversion line).

- AMS double unit (AMS-DU): 2 AMS units milking 140 cows twice daily.

- Twenty-unit MS CM Parlor (20MS): 20-unit herringbone milking parlor, milking 140 cows with MS technology (batch feeders in the milking parlor, swing-over arms, and automatic cluster removers).

- Twenty-unit HS CM Parlor (20HS): 20-unit herringbone milking parlor, milking 140 cows twice daily with HS technology (individual electronic cow feeders, swing-over arms, automatic cluster removers, electronic milk meters, automatic identification, automatic drafting, automatic washer, automatic cluster cleaning between individual cow milkings, and an electronic milk diversion line).

\section{MDSM-Bioeconomic Model}

The MDSM is a stochastic budgetary simulation model of a dairy farm. It combines animal inventory and valuation, milk supply, feed requirements, land and labor utilization, and financial and economic analysis of the production systems (Shalloo et al., 2004). The model was developed to examine key aspects of Irish grass-based systems of production and was validated by comparing the results from the model against data collected from $21 \mathrm{CM}$ Irish dairy farms. It provides the platform to assess the effects of varying biological, technical, and physical factors on farm profitability. Since its development, the model has been used to assess technology investments (Upton et al., 2015), varying pasture production systems (Patton et al., 2012), and farm expansion strategies (Hutchinson et al., 2013; McDonald et al., 2013). The model was used in the current study to quantify the economic implications of investment strategies on farm profitability across 2 farm sizes. The on-farm labor and electricity data, together with the initial capital and maintenance costs associated with each milking system, were integrated into the MDSM for the different milking systems.

\section{Model Assumptions}

Financial and biological model assumptions are outlined in Table 1. Farm sizes of 28 and 56 ha for MF and $\mathrm{LF}$, respectively, and a stocking density of 2.5 cows/ ha were applied to each farm simulation. An annual milk production of $5,000 \mathrm{~L} / \mathrm{cow}$, concentrate supplementation input of $350 \mathrm{~kg} /$ cow, grass growth of $13 \mathrm{t}$ of $\mathrm{DM} / \mathrm{ha}$, and annual replacement rate of $18 \%$ were assumed across both farm sizes and all 3 milking systems. These assumptions are based on historical Irish data. Labor was valued at $€ 12.50 / \mathrm{h}$, whereas an opportunity cost of land was included at $€ 445 /$ ha. Variable costs (concentrate feed, fertilizer, veterinarian fees, contactor charges, silage, and reseeding), fixed costs (farm maintenance and running costs, car, telephone, electricity, and insurance), and sales value (milk, cull cow, milking cow, and calf) were based on current prices (Teagasc, 2014). A 2-tier pricing structure for electricity costs (based on the period of day at which electricity consumption occurred) was assumed at €0.08 and €0.18/ $\mathrm{kWh}$ for night and day tariffs, respectively (SEAI, 2015). Milking equipment and farm infrastructure were depreciated over a 10- and 20-yr period, respectively. The investments were financed over a $10-y r$ period at an interest rate of $5 \%$. A rate of $5 \%$ was used to represent cows unsuitable for AM. This figure was based on experiences observed when training cows to the AM 
systems in the setup period (Sonck and Donkers, 1995; de Koning and Rodenburg, 2004; Jacobs and Siegford, 2012). These cows were sold as milking cull cows valued at a sale price of $€ 1,000 /$ cow and were replaced in the herd by heifers. This results in the AM systems having less mature herds in the initial years of the investment.

\section{Model Inputs}

On-Farm Labor Input. Labor data were generated from an on-farm study where 10 and 7 conventional- and automatic-milking farmers, respectively, participated in a yearlong labor study. This study involved recording of labor input data by farm operators for various defined farm duties across a range of different task categories. Data were collected between March 2014 and February 2015. All farm operators recorded the duration of the different tasks they performed throughout the day. Records were compiled on a smart phone application (developed by Acorn Labour, Co. Cork, Ireland) on 3 consecutive days on the third week of each month. The list of tasks for AM were checking AM system data, fetching cows indoors, fetching cows outdoors,

Table 1. Financial and biological assumptions used in the Moorepark Dairy Systems Model

\begin{tabular}{|c|c|}
\hline Item & Measurement \\
\hline \multicolumn{2}{|l|}{ Financial assumptions } \\
\hline Milk price $(€ / \mathrm{L})$ & 0.30 \\
\hline Price value protein:fat & $2: 1$ \\
\hline Concentrate price $(€ / t)$ & 290 \\
\hline Replacement heifer price $(€ /$ head $)$ & 1,545 \\
\hline Cull cow carcass price $(€ / \mathrm{kg})$ & 2.20 \\
\hline $\begin{array}{l}\text { Milking cows unsuitable for AMS } \\
\text { sale price }(€ / \text { head })\end{array}$ & 1,000 \\
\hline Male calf price $(€ /$ head $)$ & 50 \\
\hline Opportunity cost of land $(€ /$ ha) & 445 \\
\hline Labor costs $(€ / \mathrm{h})$ & 12.50 \\
\hline \multicolumn{2}{|l|}{ Electricity cost $(€ / \mathrm{kWh})$} \\
\hline Day tariff & 0.18 \\
\hline Night tariff & 0.08 \\
\hline \multicolumn{2}{|l|}{ Depreciation period (yr) } \\
\hline Milking equipment & 10 \\
\hline Infrastructure & 20 \\
\hline Interest rates $(\%)$ & 5 \\
\hline \multicolumn{2}{|l|}{ Biological assumptions } \\
\hline \multicolumn{2}{|l|}{ Farm size (ha) } \\
\hline Medium farm & 28 \\
\hline Large farm & 56 \\
\hline \multicolumn{2}{|l|}{ Herd size } \\
\hline Medium farm & 70 \\
\hline Large farm & 140 \\
\hline Stocking density (cows/ha) & 2.5 \\
\hline \multicolumn{2}{|l|}{ Milk production } \\
\hline $\mathrm{L} / \mathrm{cow}$ & 5,000 \\
\hline $\mathrm{kg}$ of milk solids/cow & 400 \\
\hline Concentrate fed (kg/cow) & 350 \\
\hline Grass growth $(\mathrm{t} / \mathrm{ha})$ & 13 \\
\hline Milking cows unsuitable for AMS (\%) & 5 \\
\hline Annual replacement rate $(\%)$ & 18 \\
\hline
\end{tabular}

robot cleaning maintenance, alarms, grass allocation, other dairy tasks, other enterprise tasks, and nonfarm activity. Tasks for the CM system included herding of cows pre- and postmilking, milking, milking plant and yard cleaning, grass allocation, other dairy tasks, other enterprise tasks, and nonfarm activity. The data were subsequently downloaded from the phone application to a cloud-based server and then to a Microsoft Excel database (Microsoft Corp., Redmond, WA). Data were checked monthly for abnormalities and individual farmers were contacted to clarify the circumstances surrounding any irregularity. Average herd size for the AM and CM farms were 105 (range 69-205) and 120 (range 70-160) cows, respectively.

Statistical Analysis. Labor data were analyzed using mixed procedure analysis (Proc Mixed) in SAS version 9.3 (SAS Institute Inc., Cary, NC). Farm was taken as the independent unit for analysis and, therefore, the monthly measurement was treated as a repeated measure. The following model was used:

$$
Y_{i j k}=\mu+G_{i}+M_{j}+e_{i j k}
$$

where $Y_{i j k}=$ dependent variable, $\mu=$ mean, $G_{i}=$ milking system group ( $\mathrm{i}=1$ to 2$), M_{j}=\operatorname{month}(\mathrm{j}=1$ to 12 ), and $e_{i j k}=$ residual error term.

The best fit covariance model (using AIC) was used for the analysis and residual checks were made to ensure that the assumptions of the analysis were satisfied. Where appropriate, log-transformation was used to correct nonconstant variance and skew in the residuals. Transformed data were used to examine statistical significance; however, mean values presented in this paper are taken from nontransformed data. A Tukey adjustment for multiplicity was used in making contrasts of means.

Capital Investment, Maintenance, and Running Costs. Milking machine purchase prices and service costs for $\mathrm{AM}$ and $\mathrm{CM}$ were obtained from the list prices of the manufacturers and suppliers of each system (Table 2). However, taking into consideration the recent adoption of new AM machines in Ireland, service and maintenance were also established based on the real farm data costs from countries with established AM systems. In this case an in-depth report on annual maintenance and service costs in Denmark was used as a guide (Sorensen et al., 2013). Daily running costs with regard to detergent cleaning were calculated based on purchase price and recommended usage rate. Electricity consumption was recorded using a wireless monitoring system [supplied by Carlo Gavazzi (Carlo Gavazzi Automation SpA, Lainate, Italy)] across several AM and CM systems. Wireless wide-area network (WAN) routers were used to transport the data from farm to 
Table 2. Initial machine and infrastructural investment costs and annual machine maintenance and running costs for 3 types of milking technology ${ }^{1}$ on 2 farm sizes, MF (medium farm) and LF (large farm)

\begin{tabular}{|c|c|c|c|c|c|c|}
\hline \multirow[b]{2}{*}{ Item } & \multicolumn{3}{|c|}{ MF } & \multicolumn{3}{|c|}{$\mathrm{LF}$} \\
\hline & AMS-SU & $12 \mathrm{MS}$ & $12 \mathrm{HS}$ & AMS-DU & $20 \mathrm{MS}$ & $20 \mathrm{HS}$ \\
\hline Infrastructure costs $(€)$ & 40,000 & 70,000 & 70,000 & 60,000 & 110,000 & 110,000 \\
\hline Milk cooling and storage equipment $(€)$ & 19,500 & 19,500 & 19,500 & 22,500 & 22,500 & 22,500 \\
\hline Machine service and maintenance costs $(€ / \mathrm{yr})$ & 6,000 & 1,700 & 3,000 & 12,000 & 3,000 & 4,600 \\
\hline Consumables $(€ /$ yr $)$ & 2,400 & 1,600 & 3,000 & 4,800 & 2,600 & 3,700 \\
\hline
\end{tabular}

${ }^{1} \mathrm{AMS}-\mathrm{SU}=$ single-unit automatic milking system; $12 \mathrm{MS}=12$-unit medium specification conventional milking parlor to include automatic inparlor batch feeders; $12 \mathrm{HS}=12$-unit high specification conventional milking parlor to include milk meters, electronic individual cow feeders, automatic identification, automatic cluster removers, automatic drafting, an electronic milk diversion line, automatic cluster cleaning between cow milkings, and an automatic washer; AMS-DU = double-unit automatic milking system; 20MS $=20$-unit medium specification conventional milking parlor to include automatic in-parlor batch feeders and automatic cluster removers; 20HS = 20-unit high specification conventional milking parlor to include milk meters, electronic individual cow feeders, automatic identification, automatic cluster removers, automatic drafting, an electronic milk diversion line, automatic cluster cleaning between cow milkings, and an automatic washer.

research center, where Powersoft logging and recording software (Carlo Gavazzi Automation SpA) calculated cumulative energy used $(\mathrm{kWh})$ at 15-min intervals for each on farm electricity-consuming processes. Measurements were taken on 7 and $42 \mathrm{AM}$ and $\mathrm{CM}$ farms, respectively, between April 2014 and March 2015. Milk production data of these farms were obtained from the milk purchasing companies. This allowed a comparable metric (watts per liter) be used across both farm size and milking system.

\section{Financial Metrics}

Each AM investment option was evaluated in terms of net profitability, cash flow, discounted net profit, and return on investment (ROI) for the additional investment when compared with the CM system. All analysis was completed pretax annually and over the full 10-yr of the investment.

Discounted net profit was included in the analysis to consider the time value of money, given that money decreases in value over time. This allowed the visibility of returns of each technology, over time, to be quantified. The discounted rate was set to $2.5 \%$ per annum for the 10 -yr period; this figure was decided on after evaluation of the consumer price index inflation rates in the Irish economy from 2000 to 2013 . Total discounted net profit (TDNP) was calculated using equation [1] as:

\section{$\mathrm{TDNP}=$}

Sum (Annual net profit $\times$ discount rate).

Cash flow considers the ability of each milking system described to meet financial commitments given all of the cash incomes and outgoings on an annual basis. The net cash flow from each of the 6 scenarios equaled the cash receipts minus the cash repayments. A business may be highly profitable yet fail due to negative cash flows occurring during the initial years postinvestment.

Return on investment is a financial performance measure of the efficiency of each technology investment scenario. In these calculations, the return on additional investment over the base level (MS) of investment is calculated by dividing the average difference in net profit by the difference in investment for each investment scenario. Return on investment is described by equation $[2]$ as:

\section{$\mathrm{ROI}=$}

[(net profit investment $\times$ negative net profit base)

+ (interest investment $\times$ negative interest

investment base)]/investment

$\times$ negative investment base,

where net profit $=$ the pretax net profit and base refers to MS technologies.

Investment figures for all scenarios are presented in Table 2. The ROI is used in this analysis to provide a metric of how effectively each technology-investment scenario used capital invested to generate income over the base level of investment (Upton et al., 2015).

\section{Sensitivity Analysis}

Sensitivity analysis was completed to reflect reduced capital costs, higher labor costs, higher interest rates, and higher and lower milk prices. The introduction of capital grant aid that is potentially available under the Dairy Equipment Scheme, operated by Department of 
Agriculture Food and the Marine in Ireland, at a grant rate of $40 \%$ on $\mathrm{AM}$ and $\mathrm{CM}$ equipment, up to a maximum investment of $€ 80,000$ will reduce capital costs; any investment above this figure is not subject to the $40 \%$ grant. The $40 \%$ grant also applies to milk cooling or storage facilities.

Additionally, the effects of increased labor costs were examined by increasing the cost of labor from the $€ 12.50 / \mathrm{h}$ used in the base analysis to $€ 20 / \mathrm{h}$. This reflects a future potential scarcity of on-farm labor which would result in increased labor costs. Increased interest rates above the base of $5 \%$, by 2 to $7 \%$ on the borrowed capital were included in the analysis. Finally, the effects of increased $(+€ 0.05 / \mathrm{L})$ and decreased $(-€ 0.05 / \mathrm{L})$ milk prices were tested through sensitivity analysis relative to the base price of $€ 0.30 / \mathrm{L}$.

\section{RESULTS}

\section{On-Farm Labor Input}

The total dairy labor input and the labor input for specific dairy-related tasks averaged (hours/cow per year) across AM and CM farms are shown in Table 3. Total dairy labor input was significantly less $(P<0.05)$ on AM compared with $\mathrm{CM}$ farms, with AM farmers requiring $15.8 \mathrm{~h} / \mathrm{cow}$ per year and $\mathrm{CM}$ farmers working $25 \mathrm{~h} /$ cow per year. The average daily time spent at total dairy labor input was 8.9 and $5.2 \mathrm{~h} / \mathrm{d}$ throughout the 12-mo recording period, for $\mathrm{CM}$ and $\mathrm{AM}$ farms, respectively. Reduced labor with AM can be attributed to significantly less time $(P<0.001)$ spent at the daily milking process. On average, CM farmers spent $3 \mathrm{~h} / \mathrm{d}$ (range 0.5-4.5) at the process of milking. Given the compact spring calving pattern of the farms, the duration of this task throughout the year had a similar profile to the dairy cow lactation curve, peaking in May at $4.3 \mathrm{~h} / \mathrm{d}$ and decreasing toward the end of lactation. As milking with an automatic system does not require the farmer to be present at milking time, the AM process only consumed $0.7 \mathrm{~h} / \mathrm{d}$ (range $0.2-1.1$ ). This saving in labor associated with the milking process, was partially counteracted by significantly $(P<0.001)$ more time being spent at grass allocation on farms with an AM system. The AM farmers spent, on average, $0.4 \mathrm{~h} / \mathrm{d}$ ensuring their cows were allocated the correct amount of grass in each grazing area. However, as the CM farmers were not dependent on the allocation of grass for optimum cow traffic (and had only 1 grass allocation to administer, rather than 3 ), they only spent $0.1 \mathrm{~h} / \mathrm{d}$ attending to grass allocation. Time at grass allocation was highest for the CM farms in spring $(0.28 \mathrm{~h} / \mathrm{d})$, when it was the most challenging to optimize grass utilization in poorer weather conditions. Despite labor being reduced by $9.2 \mathrm{~h} / \mathrm{cow}$ per year, daily end of work times were similar for each milking system, at $18 \mathrm{~h}$ 32 min. However, daily start times were significantly different $(P<0.05)$ with AM farms starting work 50 min later than CM farms, at $7 \mathrm{~h} 55 \mathrm{~min}$ and $7 \mathrm{~h} 5 \mathrm{~min}$, respectively.

\section{Labor Costs}

When labor rates of $€ 12.50 / \mathrm{h}$ were applied to the data, overall reduction in labor resulted in a simulated lower labor cost on the AMS-SU and AMS-DU farms at $€ 14,078$ and $€ 28,155$, respectively, compared with CM farm costs of $€ 22,179$ and $€ 44,357$ for MF and LF, respectively (Table 4). When measured as a percentage of total costs of production for specific farm systems, the trends were similar: labor on AMS-SU and AMS-DU farms accounted for 11.2 and $12.8 \%$ of total costs, respectively, whereas labor on conventional milking farms with $12 \mathrm{MS}, 12 \mathrm{HS}, 20 \mathrm{MS}$, and $20 \mathrm{HS}$ accounted for 18.8 , $17.3,21.3$, and $20.2 \%$ of total costs, respectively.

\section{Profitability}

$\boldsymbol{M F}$. The annual and TDNP for MF and LF over a 10yr period are shown in Table 5. The highest TDNP was achieved with the 12MS milking system at $€ 151,480$, which was $74 \%$ higher than AMS-SU at $€ 86,868$. The lowest TDNP was achieved by the 12HS system at $€ 60,241$. This was $31 \%$ less than the intermediate profitability of the AMS-SU. The difference in profit-

Table 3. Average dairy labor input (h/cow per year) for combined and specific dairy tasks on farms milking with automatic milking (AM) and conventional milking (CM) systems

\begin{tabular}{|c|c|c|c|c|}
\hline \multirow[b]{2}{*}{ Item } & \multicolumn{2}{|c|}{ Milking system } & \multirow[b]{2}{*}{$\mathrm{SE}$} & \multirow[b]{2}{*}{$P$-value } \\
\hline & $\mathrm{AM}$ & $\mathrm{CM}$ & & \\
\hline Total dairy labor ${ }^{1}$ & 15.8 & 25.0 & 3.00 & $<0.05$ \\
\hline Milking process ${ }^{2}$ & 2.1 & 8.1 & 0.83 & $<0.001$ \\
\hline Grass allocation $^{3}$ & 1.2 & 0.3 & 0.11 & $<0.001$ \\
\hline Other dairy tasks ${ }^{4}$ & 12.5 & 16.6 & 2.55 & NS \\
\hline
\end{tabular}

${ }^{1}$ Sum of all tasks associated with the running of the dairy enterprise.

${ }^{2}$ Milking process on automatic milking farms was the sum of time spent at robot cleaning and maintenance, checking AM data, attending to alarms and fetching any overdue cows from paddocks; milking tasks on conventional milking farms was the sum of time spent at herding cows to and from milking, milking and yard and machine cleaning;

${ }^{3}$ Task refers specifically to the process of daily grass allocation to cows in the grazing paddocks.

${ }^{4}$ Tasks associated with the operation of the dairy enterprise (excluding milking and grass allocation) such as maintenance of buildings and machinery, machinery and office work, calf and replacement heifer rearing, veterinary treatment of animals, heat detection and AI, drying off cows, and training of cows to milking system. 
Table 4. Effect of milking system type on annualized dairy farm output variables (10-yr period after installation) for 3 types of milking technology ${ }^{1}$ on 2 farm sizes, MF (medium farm) and LF (large farm)

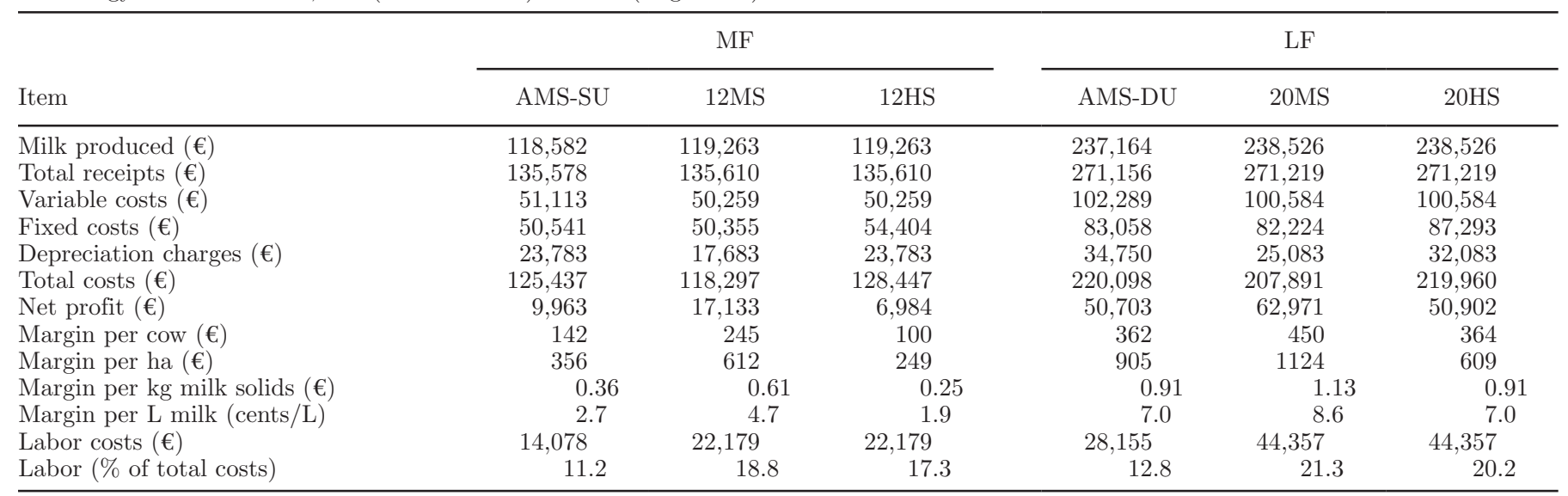

${ }^{1} \mathrm{AMS}-\mathrm{SU}=$ single-unit automatic milking system; $12 \mathrm{MS}=12$-unit medium specification conventional milking parlor to include automatic inparlor batch feeders; $12 \mathrm{HS}=12$-unit high specification conventional milking parlor to include milk meters, electronic individual cow feeders, automatic identification, automatic cluster removers, automatic drafting, an electronic milk diversion line, automatic cluster cleaning between cow milkings, and an automatic washer; AMS-DU = double-unit automatic milking system; 20MS $=20$-unit medium specification conventional milking parlor to include automatic in-parlor batch feeders and automatic cluster removers; 20HS = 20-unit high specification conventional milking parlor to include milk meters, electronic individual cow feeders, automatic identification, automatic cluster removers, automatic drafting, an electronic milk diversion line, automatic cluster cleaning between cow milkings, and an automatic washer.

ability between the milking systems was the greatest in the years immediately after the initial investment, due to the higher interest and depreciation charges for the AMS-SU and 12HS parlors. In yr 1 of the investment, AMS-SU was $€ 8,102$ less profitable than $12 \mathrm{MS}$. However, after $10 \mathrm{yr}$ that difference had reduced to $€ 4,740$ as interest on the debt was reduced greatly.

$\boldsymbol{L F}$. The annual and TDNP for MF and LF over a 10-yr period are displayed in Table 5 . Trends for the LF are similar to those for the MF, with the 20MS displaying the greatest TDNP ( $€ 559,713)$. However, AMS-DU achieved a marginally lower TDNP at $€ 449,277$ than $20 \mathrm{HS}$ at $€ 451,226$. Although trends are similar for MF and LF, the reduction in TDNP associated with AM is less in percentage terms for the LF than the MF at 20 and $43 \%$, respectively. Again, similar to MF, the AMSDU was $26 \%$ less profitable than $20 \mathrm{MS}$ in yr 1 of the investment period and this reduced to $15 \%$ by yr 10 .

\section{Cash Flow}

A summary for annual and total discounted net cash flow (TDNCF) projections are presented in Table 5 . Annual projected cash flow was positive for all investment scenarios across both farm sizes. Projections followed similar trends to profitability, with the systems which were least capital intensive and least expensive to run (12MS and 20MS) yielding more cash to meet daily financial obligations. The AM system had a reduced cash flow of 25 and $15 \%$ relative to the MS technologies in the MF and LF herd sizes, respectively.
However, AM had a 27 and $2 \%$ greater cash flow relative to the HS milking options across MF and LF herd sizes, respectively.

\section{Return on Additional Investment}

The ROI of the additional investment associated with AM and HS technologies were examined across both farm sizes. The MS technology was considered as the baseline in technology (Table 6). The investment associated with the base (MS) was $€ 123,500$ and $€ 197,500$ for $\mathrm{MF}$ and $\mathrm{LF}$, respectively. Irrespective of farm size, both AM and HS technologies had negative ROI relative to the base (MS), at -11 and $-12 \%$ for AMS-SU and AMS-DU, respectively, and $-14 \%$ for $12 \mathrm{HS}$ and $20 \mathrm{HS}$, respectively. This was primarily due to the higher cost of investment overall and lower financial returns associated with these technologies.

\section{Sensitivity Analysis}

The effect of milk price, reduced investment costs, and increased interest rates on the total farm profits are presented in Table 7 .

Milk Price. Trends were similar to that of the base study, when milk price was either increased to $€ 0.35 / \mathrm{L}$ or decreased to $€ 0.25 / \mathrm{L}$ from $€ 0.30 / \mathrm{L}$, with all systems affected similarly. All 3 investment scenarios at MF level returned a negative TDNP at the lower milk price, with MS CM parlors demonstrating the greatest ability to withstand periods of low milk price. 
Table 6. Return on additional investment (\%) above the base after the 10-yr period for three types of milking technology ${ }^{1}$ on 2 farm sizes, MF (medium farm) and LF (large farm)

\begin{tabular}{|c|c|c|c|}
\hline \multirow[b]{2}{*}{ Item } & \multicolumn{3}{|c|}{$\begin{array}{c}\text { Return on additional } \\
\text { investment over base (MS) }\end{array}$} \\
\hline & Base (MS) & AMS & HS \\
\hline $\begin{array}{l}\text { MF } \\
\mathrm{LF}\end{array}$ & $\begin{array}{l}0 \\
0\end{array}$ & $\begin{array}{l}-11 \\
-12\end{array}$ & $\begin{array}{l}-14 \\
-14\end{array}$ \\
\hline \multicolumn{4}{|c|}{$\begin{array}{l}{ }^{1} \mathrm{MS}=\text { medium specification conventional milking parlor to include } \\
\text { automatic in-parlor batch feeders (and automatic cluster removers at } \\
\mathrm{LF} \text { ), with } 12 \text { and } 20 \text { milking units at MF and LF, respectively; AMS = } \\
\text { automatic milking system with a single unit and a double unit at MF } \\
\text { and LF, respectively; HS = high-specification conventional milking } \\
\text { parlor to include milk meters, electronic individual cow feeders, auto- } \\
\text { matic identification, automatic cluster removers, automatic drafting, } \\
\text { an electronic milk diversion line, automatic cluster cleaning between } \\
\text { cow milkings, and an automatic washer, with } 12 \text { and } 20 \text { milking units } \\
\text { at MF and LF, respectively. }\end{array}$} \\
\hline
\end{tabular}

Reduction in Capital Required for Milking Technology. The effect of reducing the capital required for milking equipment through the implementation of a $40 \%$ grant, up to a maximum of $€ 80,000$ was investigated. As the investment in an AMS-SU was substantially greater than that of a $12 \mathrm{MS}$, it allowed for a greater reduction in the initial cost of the former. Consequently, the difference in TDNP between the 2 milking systems was reduced from $43 \%$ in the base scenario to $29 \%$. As the 3 original investment scenarios at LF size were greater than $€ 80,000$, the introduction of the $40 \%$ grant on milking equipment had a reduced effect on the difference in profitability of the LF systems, as described in the base scenario. All 3 scenarios reduced the original capital requirement by an equal amount $(€ 32,000)$ and reduced interest and capital repayments by similar amounts as well.

Increase in Labor Costs. The effects of increasing labor costs were examined by increasing the cost of labor from the $€ 12.50$ (used in the base scenario) to $€ 20 / \mathrm{h}$; although it reduced the profit of all systems, it had the greatest effect on the CM systems. This increased the competiveness of AM relative to the CM technologies on both farm sizes. On the MF, the differential in TDNP over the 10-yr period between AMS-SU and $12 \mathrm{MS}$ reduced from $€ 64,612$ to $€ 20,600$. Increasing labor costs resulted in a negative TDNP for $12 \mathrm{HS}$ after the $10 \mathrm{yr}$ examined. Increasing labor costs in the LF continued the trends observed previously, with 20MS achieving a TDNP of $€ 323,822$ which was $8 \%$ greater than the AMS-SU with a TDNP of $€ 301,065$, whereas $20 \mathrm{HS}$ displayed the least profit at $€ 216,407$.

Increase in Interest Rates. The effects of increasing interest rates from the $5 \%$ used in the base study to $7 \%$ were examined. Trends in TDNP remained consistent with those described previously, with MS CM 
Table 7. The effect of milk price, capital costs, labor costs, and interest rates sensitivity analysis on total discounted net profit for three types of milking technology ${ }^{1}$ on 2 farm sizes, MF (medium farm) and LF (large farm)

\begin{tabular}{|c|c|c|c|c|c|c|}
\hline \multirow[b]{2}{*}{ Item } & \multicolumn{3}{|c|}{ MF } & \multicolumn{3}{|c|}{$\mathrm{LF}$} \\
\hline & AMS-SU & $12 \mathrm{MS}$ & $12 \mathrm{HS}$ & AMS-DU & $20 \mathrm{MS}$ & $20 \mathrm{HS}$ \\
\hline \multicolumn{7}{|l|}{ Milk price } \\
\hline$€ 0.35 / \mathrm{L}$ & 263,305 & 328,116 & 237,788 & 800,518 & 911,696 & 804,281 \\
\hline$€ 0.25 / \mathrm{L}$ & $-85,955$ & $-22,418$ & $-113,469$ & 101,998 & 209,182 & 101,767 \\
\hline \multicolumn{7}{|l|}{ Milking equipment cost } \\
\hline \multicolumn{6}{|l|}{ Labor costs } & 489,907 \\
\hline \multicolumn{7}{|l|}{ Interest rates } \\
\hline $7 \%$ & 68,683 & 138,338 & 41,021 & 419,465 & 537,812 & 422,377 \\
\hline
\end{tabular}

${ }^{1} \mathrm{AMS}-\mathrm{SU}=$ single-unit automatic milking system; $12 \mathrm{MS}=12$-unit medium specification conventional milking parlor to include automatic inparlor batch feeders; $12 \mathrm{HS}=12$-unit high specification conventional milking parlor to include milk meters, electronic individual cow feeders, automatic identification, automatic cluster removers, automatic drafting, an electronic milk diversion line, automatic cluster cleaning between cow milkings, and an automatic washer; AMS-DU = double-unit automatic milking system; 20MS = 20-unit medium specification conventional milking parlor to include automatic in-parlor batch feeders and automatic cluster removers; 20HS = 20-unit high specification conventional milking parlor to include milk meters, electronic individual cow feeders, automatic identification, automatic cluster removers, automatic drafting, an electronic milk diversion line, automatic cluster cleaning between cow milkings, and an automatic washer.

technology displaying the greatest profit across the 2 farm sizes, at €69,655 and €118,347 greater than AM for MF and LF, respectively. Whereas the AM system returned intermediate profitability at MF $(€ 68,683)$, it resulted in the least profit at LF (€419,465). Increasing interest rates resulted in a reduction in competiveness for AM when compared with MS CM technologies.

\section{DISCUSSION}

When evaluating investment in milking technology, it is important to consider the effect such an investment will have on the long-term profitability and availability of cash to the farm business and the return for the additional investment made, given all of the considerations involved. Previous studies have examined the business profitability from farm accounts of AM farms and compared those of $\mathrm{AM}$ and $\mathrm{CM}$ farms over a 1- to 3-yr period (Bijl et al., 2007; Steeneveld et al., 2012), whereas others have used simulation models to examine changes in the profitability of AM systems as affected by key performance indicators of the dairy farm operation (Cooper and Parsons, 1999; Arendzen and van Scheppingen, 2000). Additionally, the decision regarding investment in AM can be analyzed as a real options problem, whereby the uncertainty and irreversibility associated with an investment is taken into consideration (Engel and Hyde, 2003; Floridi et al., 2013). Engel and Hyde (2003), when using real options analysis, found a farmers decision to invest in AM would be economically justified if a farmers CM system was 5 yr or older.

However, a common theme among these studies is their focus on AM in high-input confinement systems. Only Jago et al. (2006) investigated the economics of
AM in a pasture-based system. The current study is the first within the context of a pasture-based system to measure the effect of investing in AM technology on long-term profitability and availability of cash for the farm business, while also evaluating the returns from the increased capital investment associated with AM systems. Our study encompasses both AM and traditional herringbone CM technology, currently the norm on dairy farms at both the MF and LF sizes.

\section{Labor Usage}

Labor (both skilled and unskilled) availability is considered among the greatest challenges facing dairy farmers in expanding dairy industries (O'Brien et al., 2015a). Previous studies are in agreement that the adoption of AM technology leads to a reduction in the requirement for labor, although the level of labor reduction is less clear, varying between 19 and 30\% (Sonck, 1995; Mathijs, 2004; Bijl et al., 2007). Mathijs (2004) found that the reduction in labor, although averaging $19 \%$, varied hugely by country, with Belgian farmers reducing labor by $28 \%$ whereas Danish farmers only reduced labor by $11 \%$. Bijl et al. (2007) found that AM farms used significantly less full-time equivalent labor units than CM farms, at 1.45 compared with 1.87 , respectively. The evaluation of labor in the majority of these studies has been based on retrospective survey responses from farmers estimating their time input rather than through the capture of real-time data on-farm. O'Donovan et al. (2008) showed that the milking process accounted for $33 \%$ of total dairy tasks on Irish CM dairy farms, with the current study showing a similar proportion of labor associated with CM (32\%), but the 
proportion associated with AM was just $13 \%$ of total labor input. The 36\% reduction in labor associated with AM as measured in our study largely represented the reduction in time associated with the milking process from $3 \mathrm{~h} / \mathrm{d}$ with $\mathrm{CM}$ to $40 \mathrm{~min} / \mathrm{d}$ with $\mathrm{AM}$. This reduction of labor is a key motivator for farmers to adopt AM. A survey of early AM adopters in Australia by Kerrisk and Ravenhill (2010) found that farmers were frustrated with the quality of labor available, with farmers citing a history or ongoing staffing problems as a reason for investing in AM. Subsequently, with a lack of available skilled labor, CM systems have to endure variability of operators when the main operator requires assistance or short-term replacement.

As the number of CM farms in the current study were small, combined with the variation in the level of technology within milking parlors on the farms, it was not possible to establish what the potential labor saving associated with milking with HS relative to MS technology may be. Therefore, it should be noted that potential savings in labor associated with HS CM parlors such as automatic cluster removers, automatic washing, automatic drafting, and automatic milk diversion have not been taken into consideration, and thus are a potential limitation of the study. In the cases of automatic parlor washing and automatic drafting, the respective technology allows the task to be performed simultaneous to the task that the operator is carrying out, whereas automatic cluster removers allow a single operator to handle a greater number of milking units (O'Brien et al., 2012a).

Taking into consideration the importance of grazing management to a pasture-based AM system, it is not surprising to see a 3 -fold increase in time spent daily at grass allocation by AM farmers. However, this extra time associated with grass allocation does not counteract the savings in labor associated with the AM process. This increased time at grass allocation may lead to a greater level of pasture management, which would improve grass utilization and nutritive value (Macdonald et al., 2008; McCarthy et al., 2016) while subsequently improving profitability (French et al., 2015).

\section{Effect of Milking System on Profitability}

Automatic milking is recognized as a capital intensive investment (de Koning, 2010). The AMS-SU and AMS-DU milking equipment were 3.5 and 3.0 times more expensive than $12 \mathrm{MS}$ and 20MS milking equipment scenarios, respectively. However, given the smaller area required to house an AM system relative to a herringbone parlor, capital required for milking building infrastructure was $45 \%$ less in the AM scenarios. When the overall investment in milking (equipment and infrastructure) is taken into consideration, the AMS-SU and AMS-DU required $41 \%$ more capital than MS CM systems. This additional requirement for capital associated with AM relative to the MS technologies resulted in reductions in pretax TDNP of €64,612 and $€ 110,436$ over the 10-yr period for MF and LF herd sizes, respectively. This is a consequence of the greater interest, depreciation, energy, and maintenance costs of AM even though labor costs were significantly lower. The differences in TDNP were greatest in the initial years of the investment. Similar to profitability, cash flow was reduced with AM by 25 and $15 \%$, respectively, for MF and LF. Although TDNCF was reduced, it did not result in negative cash flow in any of the 10-yr investigated.

When compared with the equivalent technology in the HS parlor, AMS-SU and AMS-DU, though nearer in monetary terms, still required considerably more capital investment in the milking equipment than 12HS and 20HS, at 21 and 44\%, respectively. Total capital investment in milking equipment and infrastructure varied from $5 \%$ less to $5 \%$ greater when AM and HS technologies were compared at MF and LF herd sizes, respectively. Despite the greater financial outlays, the reduced labor associated with AMS-SU, resulted in a $44 \%$ greater TDNP after 10 yr for AMS-SU compared with 12HS technology at MF level. However, for LF, AMS-DU was marginally $(€ 1,949)$ less profitable than $20 \mathrm{HS}$ after $10 \mathrm{yr}$. This study showed that, when compared with a herringbone parlor of HS technology at MF, the AM system has an increased TDNP and TDNCF primarily due to the decrease in labor requirement. Thus, taking into consideration that the milking process on CM farms accounted for $32 \%$ of all dairy labor, the investment in HS parlors over AM is questionable, particularly at MF size, as it generates the least profit and the least surplus cash out of the investment scenarios examined at this farm size while still maintaining a considerable labor requirement.

However, on-farm decisions to install HS technologies are often based on a range of factors that are difficult to quantify, such as benefits in the management of labor, operator health and safety, lifestyle, and herd health, all which may be as persuasive as the economics. Whereas a high return on capital may not be provided by technology, the technology has the potential to provide milking operators with enhanced comfort and reduced fatigue (Tarrant and Armstrong, 2012). O'Donovan (2008) observed the need for the operator to remain in the parlor pit for optimum milking efficiency, thus requiring the presence of automatic drafting. Ohnstad et al. (2012) found that although capturing labor sav- 
ing with automation can be difficult, automating the components of the milking process did lead to a more structured milking routine, which may have additional benefits in terms of mastitis prevention and control. Automatic cluster removers have a particular role to play in preventing the possibility of over milking, which may otherwise lead to thickening of the skin at the teat end (Østeras and Lund, 1988) and increasing the teat end to the exposure of infection causing bacteria (O'Brien et al., 2012a). Additionally, it is difficult to ascertain the value for the additional information provided by the HS technologies, such as individual cow milk yield. The regular availability of this data combined with additional animal health benefits may lead to greater discretionary culling of underperforming cows and subsequently improved herd performance. Thus, any decision to invest in CM HS technologies will need to assess not only the economic impact, but also the desired operator working environment and potential animal health benefits.

\section{Effect of Labor and Capital Costs on Profitability}

Lightfoot and Mulvany (2002) noted that AM could become economically viable, in the context of the Australian dairy industry, if the price of units decreased by $25 \%$ and if the cost of labor increased to AUS $\$ 20$ per hour. When the investment cost was reduced in the current study, it had some positive effects in MF, but had little effect on the difference in profitability between the scenarios at LF. When the cost of labor was increased to $€ 20 / \mathrm{h}$ in the current study, the difference in TDNP between AM and MS CM changed from $€ 64,612$ and $€ 110,437$ to $€ 20,601$ and $€ 22,757$ for $\mathrm{MF}$ and LF, respectively. Thus, when the cost of labor increased, AM increased in competiveness and profitability relative to MS technology, particularly at larger herd sizes. Rotz et al. (2003) established that relatively small changes in wages for milking labor, such as $20 \%$, had little effect on profitability, but when the value of milking labor was doubled it made AM more easily justified. In the context of the current study, the combination of both increased labor costs for all milking systems and reduced AM capital costs resulted in AM having a greater $(+€ 11,100)$ and similar $(-€ 1,500)$ TDNP relative to MS technology for MF and LF, respectively.

However, irrespective of farm size, it is important to consider whole-farm profitability, particularly for farms that do not employ labor (thus the farm profitability and labor costs combined). Whereas the AM system is associated with reduced labor requirement, if this labor was not hired before the introduction of AM (family labor) the farmer does not benefit in terms of reduced la- bor costs through the introduction of an AM system. In these situations, no monetary gains are available to the farmer from reducing the requirements for labor and, thus, the farmer's disposable income will be reduced by the savings in labor and the reduction in profitability reported in the current study. This diminishes the competiveness of $\mathrm{AM}$, as the $\mathrm{CM}$ farmer is working more hours but in real terms the financial return is greater, with the AM farmer losing the difference in labor costs as well as profit. However, if the incentive in investing in an AM system is to reduce the labor requirement of the farmer, then it will achieve that objective. Then the investor prioritizes reduced labor and improved lifestyle choices over maximizing financial return.

\section{Machine Running and Maintenance Costs}

Running and maintenance costs were higher for the AM system. This was not unexpected given the magnitude of electronics and mechanics associated with AM compared with MS milking technology. A Danish report (Sorensen et al., 2013) on the maintenance and service costs of 52 AMS farms (units installed between 1999 and 2011) found a large disparity in service and maintenance cost between farms. Average costs were $€ 8,000$ per $\mathrm{AM}$ unit, ranging from $€ 2,500$ to $€ 13,400$ per robot. Whereas a correlation was not found between the maintenance costs and the number of milkings per robot, maintenance and service costs at the higher end of the spectrum may result in a prolonged machine life, due to a high annual replacement rate of parts. This type of information is not quantifiable in Ireland as of yet, with the vast majority of AM units installed in recent years. However, Steeneveld et al. (2012) concluded that the greater replacement rates of components of AM, in turn leads to the higher service and maintenance cost associated with AMS in the short term. Findings in the current study showed that electricity consumption, when measured in terms of watts per liter of milk, was $50 \%$ higher with AM. This was in agreement with the study of Upton and O'Brien (2013), which reported a 79\% increase in electricity consumption with AM when comparing parlor types on a grass-based research farm. When day and night rate tariffs were applied to ascertain a monetary value, this equated to an increase of $58 \%$ in electricity costs. Due to the high level of technology involved, a shorter lifetime is generally assumed for AM systems (Cooper and Parsons, 1999; Hyde and Engel, 2002). However, due to the more recent uptake of AM in Ireland, little knowledge exists regarding the life span of AM units; therefore, our study assumes a minimum life span of $10 \mathrm{yr}$ for all 3 milking technologies investigated. 


\section{ROI and Hurdle Rate}

The ROI calculation may be used to provide a robust approach to investment appraisal in relation to technologies over the useful life of the investment. The ROI, in coincidence with the minimal rate of return or hurdle rate, can be used as an appraisal metric to assist in the selection process of suitable investment options. A general guideline used in economic modeling is that an investment must return at least 3 to $7.5 \%$ above the costs of funds (Schall et al., 1978; Hayes and Garvin, 1982; Lang and Merino, 1993; Barker, 1999; Meier and Tarhan, 2007), which, in the current study, would be 8 to $12.5 \%$ as the loan interest rate was $5 \%$. This approach allows dairy farmers to appraise different investment options on farm while at the same time benchmarking potential investment on the farm against prospective investment that could be made outside of the farm. Based on the analysis completed in the current study, the additional investment associated with AM would never be justified when measured wholly on economic terms.

\section{Additional Considerations}

Whereas previous studies from high-input confinement AM systems have indicated production increases of 5 to $10 \%$ (de Koning, 2010), the AM systems examined in the current study were low-input systems that focus on the utilization of grazed grass, similar to the CM systems considered in the study. French et al. (2015) illustrated that every extra ton of grass DM per hectare used increased farm profit by €267/ ha. Ramsbottom et al. (2015) also contended that the most profitable system is not that with the greatest milk production, but that with the lowest total costs. Thus, the most appropriate system in the Irish scenario is the low-cost grass-based system of milk production. However, if the AM technology were to be examined in the context of a grass-based system with higher levels of concentrate supplementation, the potential economic outcome may differ as a result of a more targeted feeding and milking approach of individual cows, as in the studies of André et al. (2010a,b). Furthermore, the introduction of AM may lead to potential animal health benefits in the form of (a) reduced lameness, as the cows are no longer herded from the pasture and instead walk at their own pace to the dairy, and (b) reduction in cases of mastitis possibly contributed by the reduced transfer of bacteria from cow to cow during milking, less over milking and the early detection of potential mastitis cases from the milking robot-generated data. Geary et al. (2012) demonstrated that reducing milk SCC had the potential to increase net farm profit by
3.6 cents $/ \mathrm{kg}$ of milk. Additionally, the availability of data on the individual cow at the each milking may lead to more selective breeding and culling of cows. Despite the potential benefits of such information, it is difficult to establish the monetary value of such data to the farmer, as it is at the discretion of the individual what role the available data plays in supporting decision making on the farm.

With the removal of EU milk quotas and a proposed increase of 50\% in milk output by 2020 (DAFM, 2010), dairy farmers will be looking to grow their businesses as cost effectively as possible. A study of 800 Irish dairy farms showed considerable underutilization of existing animals, land, and labor with considerable scope for increased productivity (O'Donnell et al., 2008). Taking into consideration the average herd size of 64.6 cows of the farms surveyed by O'Donnell et al. (2008) and the proposed increase of $50 \%$ in milk output by 2020 (DAFM, 2010), AM would be an option for many of those farmers. Therefore, farmers will need to make decisions to take into consideration the key areas that will influence those decisions, such as (a) farm growth using AM would require considerable investment in milking equipment and (b) the MS and HS CM technologies featured in the current study have the potential to milk considerably more cows than presented, with no additional investment required in milking technologies, although additional labor would be required. This additional labor combined with the increased labor associated with CM is a social cost to be considered, particularly as herds expand. Therefore, decision-making regarding investment in new milking technology needs to encompass the desired workload of the individual, available skilled labor, and the economic goals of the farm.

\section{CONCLUSIONS}

The objective of this paper was to identify the profitability over a 10-yr period following an initial investment in an AM system relative to 2 specifications of CM technologies, across 2 farm sizes, in a pasture-based system. The results indicated that, at both farm sizes, the investment in AM technology yielded less profit than MS CM technology, whereas similar investment in HS CM technology yielded less and similar profits than $\mathrm{AM}$ at a MF and at LF, respectively. Although the AM system was associated with greater interest and capital repayments, depreciation, maintenance, and running costs and lower profitability, the lower labor associated with AM still make it an attractive lifestyle choice for some farmers. The analysis suggested that profitability should not be the reason for investing in AM technologies. Thus, any decision to invest in AM should consider 
several factors, such as the availability of skilled labor, lifestyle sought by the farmer, interest in technology, and the initial capital investment requirement by the milking system.

\section{ACKNOWLEDGMENTS}

The authors acknowledge the participation and cooperation of the farmers during the collection of the onfarm labor data. We also wish to acknowledge that the research leading to these results has received funding from the European Union's Seventh Framework Program managed by REA-Research Executive Agency, http://ec.europa.eu/research/rea [(FP7/2007-2013), under grant agreement no. SME-2012-2-314879].

\section{REFERENCES}

André, G., P. B. M. Berentsen, B. Engel, C. J. A. M. de Koning, and A. G. J. M. Oude Lansink. 2010a. Increasing the revenues from automatic milking by using individual variation in milking characteristics. J. Dairy Sci. 93:942-953.

André, G., P. B. M. Berentsen, G. Van Duinkerken, B. Engel, and A. G. J. M. O. Lansink. 2010b. Economic potential of individual variation in milk yield response to concentrate intake of dairy cows. J. Agric. Sci. 148:263-276.

Arendzen, I., and A. T. J. van Scheppingen. 2000. Economical sensitivity of four main parameters defining the room for investment of automatic milking systems on dairy farms. Pages 201-211 in Robotic Milking, Proc. Int. Symp. H. Hogeveen and A. Meijering ed. Wageningen Pers., Wageningen, the Netherlands.

Barker, K. 1999. Investment policy and the employers' perspective. Pages 301-308 in Investment, Growth, and Employment: Perspectives for Policy. C. Driver and P. Temple, ed. Routledge, London, UK.

Bijl, R., S. R. Kooistra, and H. Hogeveen. 2007. The profitability of automatic milking on Dutch dairy farms. J. Dairy Sci. 90:239-248.

Cooper, K., and D. J. Parsons. 1999. An economic analysis of automatic milking using a simulation model. J. Agric. Eng. Res. $73: 311-321$.

DAFM. 2010. Food harvest 2020-A Vision for Irish Agri-Food and Fisheries. Department of Agriculture Food and the Marine, Dublin, Ireland.

de Koning, K. D. 2010. Automatic milking: Common practice on dairy farms. Pages 59-63 in Proc. 2nd North Am. Conf. Robotic Milking, Toronto, Canada. Precision Dairy Operators, Elora, Canada.

de Koning, K. 2011. Automatic milking: Common practice on over 10,000 dairy farms worldwide. Pages 14-31 in Proceedings of Dairy Research Foundation Symposium 2011. The University of Sydney, Camden, Australia, Camden, NSW, Australia. P. Celi, ed University Printing Services Sydney, Sydney, Australia.

de Koning, K., and J. Rodenburg. 2004. Automatic milking: State of the art in Europe and North America. Pages 27-37 in Proceedings of Automatic Milking: A Better Understanding. A. Meijering, $\mathrm{H}$. Hogeveen, and C. J. A. M. de Koning, ed. Wageningen Academic Publishers, Wageningen, the Netherlands.

Dijkhuizen, A. A., R. B. M. Huirne, S. B. Harsh, and R. W. Gardner. 1997. Economics of robot application. Comput. Electron. Agric. $17: 111-121$.

Dillon, P., J. R. Roche, L. Shalloo, and B. Horan. 2005. Optimising financial return from grazing in temperate pastures. Pages 131-147 in Proceedings of Satellite Workshop Xxth Int.Grassland Congress, Cork, Ireland. J. J. Murphy ed. Wageningen Pers., Wageningen, the Netherlands.

Engel, P. D., and J. Hyde. 2003. A real options analysis of automatic milking systems. Agric. Resour. Econ. Rev. 32:282-294.
Floridi, M., F. Bartolini, J. Peerlings, N. Polman, and D. Viaggi. 2013. Modelling the adoption of automatic milking systems in NoordHolland. Bio-Based Appl. Econ. 2:73-90.

French, P., L. Hanrahan, and L. Shalloo. 2015. Principles of sustainable dairy expansion. Pages 9-14 in Irish Dairying; Sustainable Expansion. Teagasc Moorepark, Cork, Ireland.

Geary, U., N. Lopez-Villalobos, N. Begley, F. McCoy, B. O'Brien, L. O'Grady, and L. Shalloo. 2012. Estimating the effect of mastitis on the profitability of Irish dairy farms. J. Dairy Sci. 95:3662-3673.

Greenall, R., E. Warren, and M. Warren. 2004. Integrating automatic milking installations (AMIs) into grazing systems - Lessons from Australia. Pages 273-279 in Proceedings of Automatic Milking: A Better Understanding. A. Meijering, H. Hogeveen, and C. J. A. M. de Koning, ed. Wageningen Academic Publishers, Wageningen, the Netherlands.

Hanson, G. D., S. A. Ford, R. L. Parsons, L. C. Cunningham, and L. D. Muller. 1998. Increasing intensity of pasture use with dairy cattle: An economic analysis. J. Prod. Agric. 11:175-179.

Hayes, R. H., and D. A. Garvin. 1982. Managing as if tomorrow mattered. Harv. Bus. Rev. 60:70-79.

Hofstetter, P., H.-J. Frey, C. Gazzarin, U. Wyss, and P. Kunz. 2014. Dairy farming: Indoor v. pasture-based feeding. J. Agric. Sci. 152:994-1011.

Hogeveen, H., K. Heemskerk, and E. Mathijs. 2004. Motivations of Dutch farmers to invest in an automatic milking system or a conventional milking parlour. Pages 56-61 in Proc. Automatic Milking: A Better Understanding. A. Meijering, H. Hogeveen, and C. J. A. M. de Koning, ed. Wageningen Academic Publishers, Wageningen, the Netherlands.

Hutchinson, I. A., L. Shalloo, and S. T. Butler. 2013. Expanding the dairy herd in pasture-based systems: The role of sexed semen use in virgin heifers and lactating cows. J. Dairy Sci. 96:6742-6752.

Hyde, J., and P. Engel. 2002. Investing in a robotic milking system: A Monte Carlo simulation analysis. J. Dairy Sci. 85:2207-2214.

Jacobs, J. A., and J. M. Siegford. 2012. Lactating dairy cows adapt quickly to being milked by an automatic milking system. J. Dairy Sci. 95:1575-1584.

Jago, J., A. Jackson, K. Davis, R. Wieliczko, P. Copeman, I. Ohnstad, R. Claycomb, and M. Woolford. 2004. Is automatic milking possible with a $100 \%$ pasture diet. Page 307 in Proc. Automatic Milking: A Better Understanding. A. Meijering, H. Hogeveen, and CJ A M. de Koning, ed. Wageningen Academic Publishers, Wageningen, the Netherlands.

Jago, J., and M. Woolford. 2002. Automatic milking systems: An option to address the labour shortage on New Zealand dairy farms? Proc. N. Z. Grassl. Assoc. 64:39-44.

Jago, J. G., K. L. Davis, M. Newman, and M. W. Woolford. 2006. An economic evaluation of automatic milking systems for New Zealand dairy farms. Proc. N.Z. Soc. Anim. Prod. 66:263-269.

Kerrisk, K., and B. Ravenhill. 2010. Learnings around automatic milking system adoption on-farm. Pages 45-49 in Proc. Australian Dairy Conference. Dairy Australia, Victoria, Australia.

Lang, H. J., and D. N. Merino. 1993. The selection process for capital projects. John Wiley \& Sons, New York, NY.

Lightfoot, C., and J. Mulvany. 2002. Farming systems for automatic milking in Australia. Occasional report prepared for Dairy Australia, Melbourne, Australia.

Lock, A. L., and P. C. Garnsworthy. 2003. Seasonal variation in milk conjugated linoleic acid and $\Delta^{9}$ - desaturase activity in dairy cows. Livest. Prod. Sci. 79:47-59.

Lyons, N. A., K. L. Kerrisk, and S. C. Garcia. 2013. Comparison of 2 systems of pasture allocation on milking intervals and total daily milk yield of dairy cows in a pasture-based automatic milking system. J. Dairy Sci. 96:4494-4504.

Macdonald, K. A., J. W. Penno, J. A. S. Lancaster, and J. R. Roche. 2008. Effect of stocking rate on pasture production, milk production, and reproduction of dairy cows in pasture-based systems. J. Dairy Sci. 91:2151-2163.

Mathijs, E. 2004. Socio-economic aspects of automatic milking. Pages 46-55 in Proceedings of Automatic Milking: A Better Understand- 
ing. A. Meijering, H. Hogeveen, and C. J. A. M. de Koning, ed. Wageningen Academic Publishers, Wageningen, The Netherlands.

McCarthy, B., L. Delaby, K. M. Pierce, J. McCarthy, C. Fleming, A. Brennan, and B. Horan. 2016. The multi-year cumulative effects of alternative stocking rate and grazing management practices on pasture productivity and utilization efficiency. J. Dairy Sci. 99:3784-3797.

McDonald, R., L. Shalloo, K. M. Pierce, and B. Horan. 2013. Evaluating expansion strategies for startup European Union dairy farm businesses. J. Dairy Sci. 96:4059-4069.

Meier, I., and V. Tarhan. 2007. Corporate investment decision practices and the hurdle rate premium puzzle. Accessed Nov. 18, 2015. http://papers.ssrn.com/sol3/papers.cfm?abstract_id=960161.

Moyes, K. M., L. Ma, T. K. McCoy, and R. R. Peters. 2014. A survey regarding the interest and concern associated with transitioning from conventional to automated (robotic) milking systems for managers of small- to medium-sized dairy farms. Prof. Anim. Sci. 30:418-422.

Nieman, C. C., K. Steensma, J. Rowntree, D. Beede, and S. Utsumi. 2015. Differential response to stocking rates and feeding by two genotypes of Holstein-Friesian cows in a pasture-based automatic milking system. Animal 9:2039-2049.

O'Brien, B., P. Clarke, T. O'Dwyer, D. Gleeson, and J. Deming. 2015a. Labour requirements on dairy farms. Pages 133-134 in Irish Dairying; Sustainable Expansion. Teagasc Moorepark, Cork, Ireland.

O'Brien, B., C. Foley, and J. Shortall. 2015b. Robotic milking in a pasture based system. Pages 18-19 in TResearch: Sustainable dairy expansion. Teagasc Oakpark, Carlow, Ireland.

O'Brien, B., J. Jago, J. P. Edwards, N. Lopez-Villalobos, and F. McCoy. 2012a. Milking parlour size, pre-milking routine and stage of lactation affect efficiency of milking in single-operator herringbone parlours. J. Dairy Res. 79:216-223.

O'Brien, D., L. Shalloo, J. Patton, F. Buckley, C. Grainger, and M. Wallace. 2012b. Evaluation of the effect of accounting method, IPCC v. LCA, on grass-based and confinement dairy systems greenhouse gas emissions. Animal 6:1512-1527.

O'Donnell, S., L. Shalloo, A. M. Butler, and B. Horan. 2008. A survey analysis of opportunities and limitations of Irish dairy farmers. J. Farm Manag. 13:419-434.

O'Donovan, K. 2008. Labour efficiency on Irish dairy farms. PhD thesis. School of Agriculture, Food Science and Veterinary Medicine, National University of Ireland, University College Dublin.

O'Donovan, K., B. O'Brien, D. J. Ruane, J. Kinsella, and D. Gleeson. 2008. Labour input on Irish dairy farms and the effect of scale and seasonality. J. Farm Manag. 13:38-53.

Ohnstad, I., R. G. M. Olde Riekerink, P. Hogewerf, C. A. J. M. de Koning, and H. W. Barkema. 2012. Short communication: Effect of automatic postmilking teat disinfection and cluster flushing on the milking work routine. J. Dairy Sci. 95:2567-2570.

Østeras, O., and A. Lund. 1988. Epidemiological analyses of the associations between bovine udder health and milking machine and milking management. Prev. Vet. Med. 6:91-108.

Patton, D., L. Shalloo, K. M. Pierce, and B. Horan. 2012. A biological and economic comparison of 2 pasture-based production systems on a wetland drumlin soil in the northern region of Ireland. J. Dairy Sci. 95:484-495.

Ramsbottom, G., B. Horan, D. P. Berry, and J. R. Roche. 2015. Factors associated with the financial performance of spring-calving, pasture-based dairy farms. J. Dairy Sci. 98:3526-3540.
Reijs, J., C. Daatselaar, J. Helming, J. Jager, and A. Beldman. 2013. Grazing dairy cows in north-west Europe. LEI Report 2013-001. LEI Wageningen UR, The Hague, the Netherlands.

Rotz, C. A., C. U. Coiner, and K. J. Soder. 2003. Automatic milking systems, farm size, and milk production. J. Dairy Sci. 86:41674177.

Schall, L. D., G. L. Sundem, and W. R. Geijsbeek. 1978. Survey and Analysis of Capital Budgeting Methods. J. Finance 33:281-287.

SEAI. 2015. Domestic fuels comparison of energy costs. Sustainable Energy Authority of Ireland (SEAI), Dublin, Ireland. Accessed Nov. 18, 2015. http://www.seai.ie/Publications/Statistics_ Publications/Fuel_Cost_Comparison/Domestic-Fuel-CostComparisons.pdf.

Shalloo, L., P. Dillon, M. Rath, and M. Wallace. 2004. Description and validation of the Moorepark Dairy System Model. J. Dairy Sci. 87:1945-1959.

Sonck, B. 1995. Labour research on automatic milking with a humancontrolled cow traffic. Neth. J. Agric. Sci. 43:261-285.

Sonck, B., and J. H. W. Donkers. 1995. The milking capacity of a milking robot. J. Agric. Eng. Res. 62:25-38.

Sorensen, M., O. Lund, and J. Krog. 2013. Kvaeginfo 2381: Omkostninger til vedligehold ved malkerobotter. Accessed Dec. 9, 2015. https:// www.landbrugsinfo.dk/byggeri/stalde/kvaegstalde/kostalde/ ams-automatiske-malkesystemer/sider/2381-omkostninger-tilvedligehold-ved-malkerobotter.aspx.

Steeneveld, W., L. W. Tauer, H. Hogeveen, and A. G. J. M. Oude Lansink. 2012. Comparing technical efficiency of farms with an automatic milking system and a conventional milking system. J. Dairy Sci. 95:7391-7398.

Tarrant, K. A., and D. P. Armstrong. 2012. An economic evaluation of automatic cluster removers as a labour saving device for dairy farm businesses. Australas. Farm Bus. Manag. J. 9:43-48.

Teagasc. 2014. Management data for farm planning. Teagasc, Oak Park, Carlow, Ireland.

Thomsen, P. T., S. Ostergaard, H. Houe, and J. T. Sorensen. 2007. Loser cows in Danish dairy herds: Risk factors. Prev. Vet. Med. 79:136-154.

Upton, J., M. Murphy, I. J. M. De Boer, P. W. G. Groot Koerkamp, P. B. M. Berentsen, and L. Shalloo. 2015. Investment appraisal of technology innovations on dairy farm electricity consumption. J. Dairy Sci. 98:898-909.

Upton, J., and B. O'Brien. 2013. Analyis of energy consumption in robotic milking. Pages 465-470 in Proceedings of Precision Livestock Farming '13. D. Berckmans and J. Vandermeulen, ed. Katholieke Universiteit Leuven, Leuven, Belgium.

van den Pol van Dasselaar, A., M. DeHaan, A. Evers, and A. P. Philipsen. 2010 Simulation effect of grass intake on the farmer's income. Pages 100-102 in Proceedings of Grassland Science in Europe. H. Schnyder, J. Isselstein, F. Taube, K. Auerswald, J. Schellberg, M. Wachendorf, A. Herrmann, M. Gierus, N. Wrage, and A. Hopkins, ed. Universität Göttingen Publishers, Kiel, Germany.

van Dooren, H., L. Heutinck, and G. Biewenga. 2004. Combining automatic milking and grazing. Practice in the Netherlands. Pages 305-306 in Proc. Automatic Milking: A Better Understanding. A. Meijering, H. Hogeveen, and C. J. A. M. de Koning, ed. Wageningen Academic Publishers, Wageningen, the Netherlands. 